\title{
Influence of Modes of Climate Variability on Global Temperature Extremes
}

\author{
JESSE KENYON \\ Nicholas School for the Environment and Earth Sciences, Duke University, Durham, North Carolina \\ Gabriele C. Hegerl \\ School of GeoSciences, The University of Edinburgh, Edinburgh, United Kingdom
}

(Manuscript received 28 June 2007, in final form 21 December 2007)

\begin{abstract}
The influence of large-scale modes of climate variability on worldwide summer and winter temperature extremes has been analyzed, namely, that of the El Niño-Southern Oscillation, the North Atlantic Oscillation, and Pacific interdecadal climate variability. Monthly indexes for temperature extremes from worldwide land areas are used describe moderate extremes, such as the number of exceedences of the 90th and 10th climatological percentiles, and more extreme events such as the annual, most extreme temperature. This study examines which extremes show a statistically significant $(5 \%)$ difference between the positive and negative phases of a circulation regime. Results show that temperature extremes are substantially affected by large-scale circulation patterns, and they show distinct regional patterns of response to modes of climate variability. The effects of the El Niño-Southern Oscillation are seen throughout the world but most clearly around the Pacific Rim and throughout all of North America. Likewise, the influence of Pacific interdecadal variability is strongest in the Northern Hemisphere, especially around the Pacific region and North America, but it extends to the Southern Hemisphere. The North Atlantic Oscillation has a strong continent-wide effect for Eurasia, with a clear but weaker effect over North America. Modes of variability influence the shape of the daily temperature distribution beyond a simple shift, often affecting cold and warm extremes and sometimes daytime and nighttime temperatures differently. Therefore, for reliable attribution of changes in extremes as well as prediction of future changes, changes in modes of variability need to be accounted for.
\end{abstract}

\section{Introduction}

Extreme weather events, such as floods or heat waves, have great societal impact. However, changes in the probability of extreme events are more difficult to diagnose and understand than changes in mean climate. Apart from the greater statistical sampling variability in rare events, other difficulties are that high-resolution temporal data and more sophisticated methods are needed to analyze changes. A need for data that reside on the moderately extreme side of climate phenomena, yet comprise large enough samples to diagnose and detect changes, resulted in the development of so-called climate extremes indexes (Frich et al. 2002; STARDEX

Corresponding author address: Gabriele C. Hegerl, School of GeoSciences, The Grant Institute, The University of Edinburgh, The King's Buildings, West Mains Road, Edinburgh EH9 3JW, United Kingdom.

E-mail: gabi.hegerl@ed.ac.uk
2005; Alexander et al. 2006). Early work in the development of climate extremes indexes was done by the European Climate Assessment (Klein Tank et al. 2002). Frich et al. (2002) built on this early work to expand analysis beyond Europe. A further intensive, international effort to develop and acquire a global dataset of these indexes was performed by the Expert Team on Climate Change Detection, Monitoring and Indices (ETCCDMI), which is part of the joint World Meteorological Organization (WMO) Commission for Climatology and Climate Variability and Predictability (CLIVAR) program (Alexander et al. 2006). This initiative resulted in an initial suite of 27 climate indexes, which described moderately frequent to, in some cases, more rare extreme events and also provided free software for calculating the indexes. Such indexes can be an absolute event, such as the hottest day of each year or a percentile-based index that describes the number of days a threshold is exceeded. Threshold indexes that are based on the exceedence of, for example, the 90th 
or 10th percentile of climatology allow for a comparison of changes in extremes in climatologically different regions (STARDEX 2005). However, they have to be calculated with caution to avoid inhomogeneities between the base period used to calculate thresholds and subsequent periods (Zhang et al. 2005). In this study, we use both types of indexes as described in section $2 \mathrm{~b}$. Since inception, the list of indexes and their definitions have been evolving, and they continue to be updated.

It has been well established that the large-scale circulation patterns of El Niño-Southern Oscillation (ENSO) and the North Atlantic Oscillation (NAO) have a regional scale effect on mean annual temperature and precipitation over North America. It is known, for instance, that the extreme northwestern United States, western Canada, and southern Alaska experience warmer wintertime temperatures during an El Niño, whereas the southeastern United States experiences wetter and cooler conditions (e.g., Kiladis and Diaz 1987; Rasmusson and Carpenter 1982; Deser and Wallace 1987). However, El Niño episodes influence the weather worldwide. For example, they bring warmer-than-normal conditions to southeastern Asia and India during the months of December through February (Deser and Wallace 1990). During the months of June through August, Brazil and the tropical west coast of South America experience warmer-than-normal conditions. In a La Niña phase, cooler-than-normal temperatures affect west equatorial Africa and Japan. During the boreal summer, west equatorial Africa is also cooler, and southeastern Africa and Southeast Asia also experience cooler-than-normal mean temperatures (Rasmusson and Carpenter 1982; Deser and Wallace 1987, 1990; see also www.cpc.noaa.gov/products/precip/ CWlink/MJO/enso.shtml).

The positive phase of the NAO is known to bring stronger westerlies over Europe in wintertime, which results in warmer surface temperatures and increased storminess (Hurrell et al. 2003). Over North America, winters during a positive NAO phase bring warmer temperatures for much of the continental United States, whereas regions in the eastern Canadian provinces experience anomalously cooler temperatures. Wettstein and Mearns (2002) found a robust relationship between North American winter temperatures and the NAO phases. They also found a dipole in which New England experienced warmer winters during a positive NAO phase, whereas Quebec had colder temperatures, which reflect the findings of Hurrell and van Loon (1997).

Pacific interdecadal variability is a long-lived phenomenon with regional effects throughout the Pacific basin and even globally, which is described by a number of related indexes. The mechanisms involved and similarities and differences to El Niño are still being investigated (Mantua and Hare 2002; White et al. 2003; Meehl and $\mathrm{Hu}$ 2006; Jin 2001). Pacific decadal oscillation (PDO) has been used to refer to both the climate phenomenon and to an SST-based index that measures it (Mantua et al. 1997). The PDO is also called the Interdecadal Pacific Oscillation (IPO; see Power et al. 1999). The PDO and IPO are defined somewhat differently but both describe basically the same phenomena of a decadally varying "El Niño-like" pattern of SST variability in the Pacific. The IPO has been shown to influence Australian rainfall (Arblaster et al. 2002). Other references refer to a North Pacific Oscillation (NPO; Gershunov and Barnett 1998), whereas Deser et al. (2004) use an index they call the North Pacific index (NPI) based on an average of sea level pressure (SLP) anomalies in the North Pacific. We use the NPI in this study (see section 2a), but the results were similar (although different in sign as expected) if using a PDO index. The decadal-scale oscillation consists of phases that are either preferentially positive or negative, can last 20-30 yr, and are marked by sharp transitions from one phase to the next (Mantua et al. 1997; Deser et al. 2004). This is in contrast to ENSO, which switches phase more frequently. Characteristics of the positive phases of the PDO and the negative phase of the NPI are cool SSTs in the North Pacific and an associated, deepened Aleutian low with enhanced westerlies for the central North Pacific (Mantua et al. 1997; Gershunov and Barnett 1998; Deser et al. 2004; Minobe 1997). This tends to coincide with warm conditions in the eastern tropical Pacific (e.g., Zhang et al. 1997). A positive phase of the PDO is closely associated with a negative phase of the NPI because the latter index is defined by anomalies of sea level pressure over the North Pacific (Deser et al. 2004; Trenberth and Hurrell 1994). The cyclonic flow of the deeper low brings warmer, moist air to the eastern North Pacific, resulting in warmer-than-usual wintertime temperatures for negative NPI conditions over large parts of northern North America (Mantua et al. 1997; Gershunov and Barnett 1998; Mantua and Hare 2002). Additionally, southern India and subequatorial Africa experience warmer temperatures during positive PDO phases, whereas the southeastern United States and coastal Asia experience anomalously cool temperatures (Mantua et al. 1997; Mantua and Hare 2002, their Fig. 3). The discussion of Pacific decadal climate variability is closely connected to impacts these modes cause. For example, the discovery of the PDO first grew out of its impact on ecosystem changes, especially salmon harvests in the Pacific Northwest (Mantua et al. 1997, their 
references). Similarly, notions of the IPO grew out of studies of Australian rainfall and the influence this mode of variability was having (Arblaster et al. 2002).

Thompson and Wallace (2001) showed that the Northern Annular Mode (NAM; Thompson and Wallace 1998, 2000) exerts a strong influence on wintertime climate over large parts of the Northern Hemisphere, substantially affecting day-to-day variability. They demonstrate that the probability of many daily temperature extremes changes sharply depending on the state of the NAM, and their results suggest that a shift in mean temperature associated with NAM variability explains only part of the observed differences in the occurrence of temperature extremes because of a high or low NAM index. There has also been work on the influences of circulation on regional temperature extremes. For example, Scaife et al. (2008) find that the NAO correlates with fewer cold wintertime extremes over Europe, based on observations and model data.

A study of the effects of El Niño on present and future heat waves, heavy precipitation, and frost days over the United States has been recently published (Meehl et al. 2007). However, there has been little study of large-scale changes in observed temperature extremes, largely because large-scale observations for climate extremes have been difficult to obtain prior to the Frich et al. (2002) index project and subsequent ETCCDMI project (Alexander et al. 2006). Therefore, the global pattern and extent of influence of modes of climate variability on temperature extremes is the subject of this paper.

The paper is organized as follows: section 2 discusses the station-based indexes for climate extremes and the indexes of circulation used. Section 3 briefly describes the method of analysis. Response of temperature extremes to individual modes of circulation are presented in section 4 . Section 5 discusses the linearity of the results and how circulation influences the shape of temperature distributions. Conclusions are discussed in the last section.

\section{Data}

\section{a. Circulation patterns}

A variety of indexes are available to characterize the state of major modes of climate variability. For the El Niño-Southern Oscillation phenomenon, we use the cold tongue index (CTI; Fig. 1a) obtained from the Joint Institute for the Study of the Atmosphere and Ocean (JISAO) Web site (http://jisao.washington.edu/) at the University of Washington. The index is a measure of monthly SST anomalies over a region of the Pacific Ocean, which straddles the equator from $6^{\circ} \mathrm{S}$ to $6^{\circ} \mathrm{N}$, spans from $180^{\circ}$ to $90^{\circ} \mathrm{W}$, and runs from 1849 to the recent past (we used data to 2005). Each monthly value is the average anomaly for the $2702^{\circ} \times 2^{\circ}$ gridboxes over this region, taken with respect to the 1950 79 climatology. The global mean SST anomaly is subtracted to avoid the influence of global mean SST changes. This also should reduce the influence of changes in measurement, such as the post World War II change from bucket measurements to engine-intake (Folland and Parker 1995). We chose this index because it has been used in other studies of interannual and decadal variability (Zhang et al. 1997), and it spans a longer time horizon than the commonly used Niño-3.4 index, which is only available from 1950. (The Niño-3.4 index is calculated from SSTs in the tropical pacific bounded from $120^{\circ} \mathrm{W}$ to $170^{\circ} \mathrm{W}$ and from $5^{\circ} \mathrm{S}$ to $5^{\circ} \mathrm{N}$. See the Center for Climate Prediction Web site: www. cpc.noaa.gov/data/indices/sstoi.indices.) However, the results of our study are robust to using the Niño-3.4 index, with a slight tendency toward a stronger response to Niño-3.4. We, nevertheless, prefer the teleconnections to be supported by a longer time horizon.

We construct an index for warm season and cold season mean El Niño variability by averaging monthly values from May through October for the boreal warm season, and from November through April for the boreal cold season. The seasonal means of the CTI are compared against a positive and a negative threshold ( \pm 0.3 of the standard deviation of the CTI's monthly variability). If a season exceeds the positive threshold, it is considered to be El Niño-like, although if it is less than the negative threshold it is considered to be $\mathrm{La}$ Niña-like. All other seasons are considered neutral. The value of 0.3 as a threshold was chosen as a compromise between wishing to capture a large sample of years for each regime while ignoring years that are truly neutral. This sets the bar for an El Niño lower than usual definitions with a dynamical focus, including years that are not full dynamical ENSO years but do have anomalous SSTs in the tropical Pacific. Figure 1d shows the CTI converted into a time series of on/off switches for each cold half year. Because the climate extremes indexes being used typically do not extend into the nineteenth century, and because the CTI contains a large number of missing data through the nineteenth century, the present study utilizes a subset of years from 1896 to 2004.

Pacific interdecadal variability is represented by the NPI. The NPI (see Fig. 1b) was obtained from Clara Deser at National Center for Atmospheric Research (NCAR) and is defined by Trenberth and Hurrell (1994) as the area-averaged wintertime [DecemberMarch (DJFM)] sea level pressure over the North Pa- 


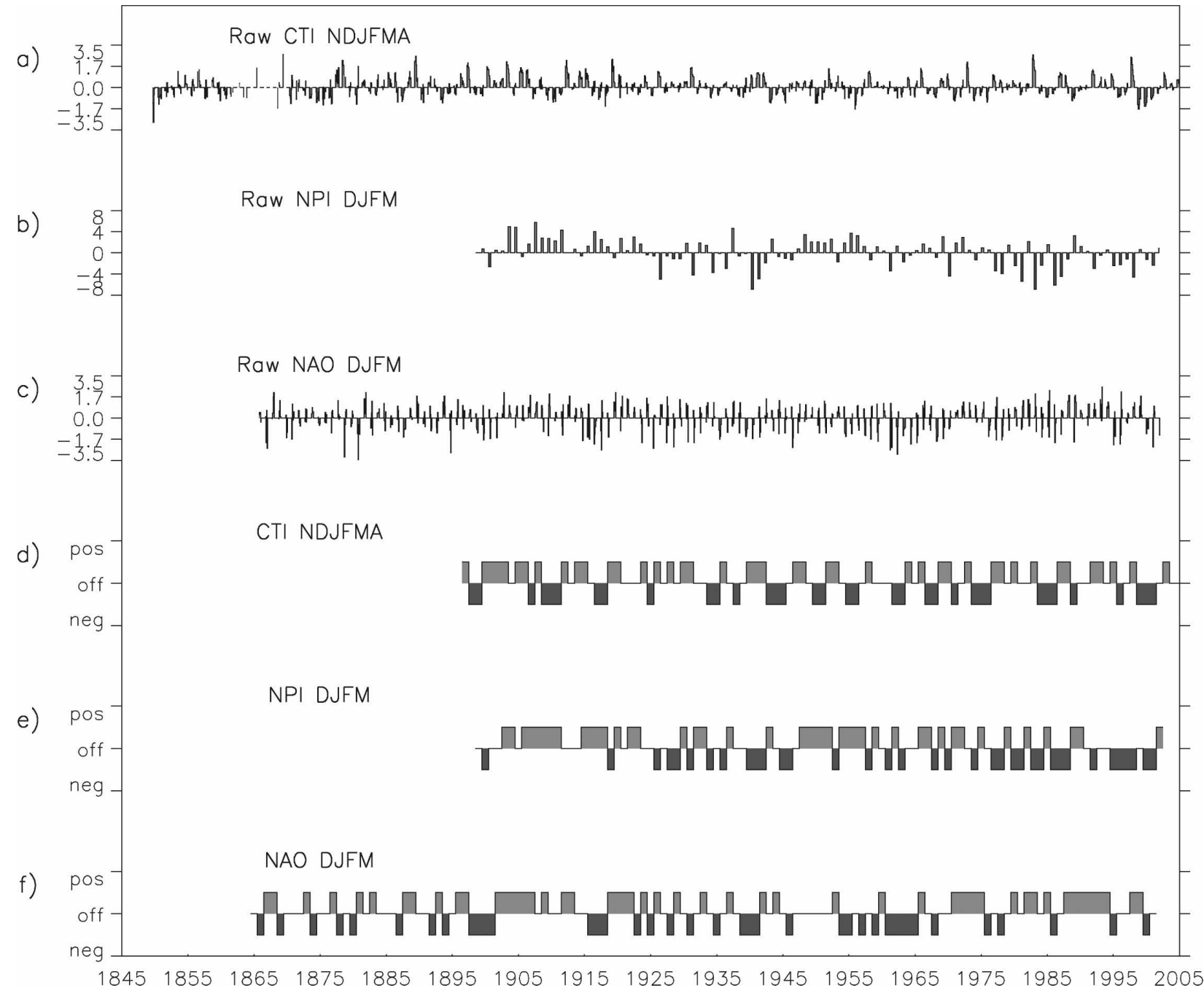

FIG. 1. Indexes for large-scale circulations used in this paper: (a) the CTI of monthly SST anomalies for the $6^{\circ} \mathrm{S}-6^{\circ} \mathrm{N}$ Pacific equatorial region with units in Celsius, (b) the NPI consisting of an area-averaged SLP for the average of DJFM, mean removed and units are mb, and (c) the NAO index for DJFM. Panels (d), (e), and (f) show the same indexes, which are now processed in to seasonal on/off indexes such that if a seasonal value exceeds $+0.3 \mathrm{std} \mathrm{dev}$, it is positive phase; $<-0.3 \mathrm{std}$ dev is negative phase; otherwise it is neutral.

cific region bounded by $30^{\circ}-65^{\circ} \mathrm{N}$ and $140^{\circ} \mathrm{E}-160^{\circ} \mathrm{W}$. Another commonly used index is the PDO. The PDO index is the leading EOF of SSTs from the extratropical North Pacific basin (Mantua et al. 1997). The NPI is very similar to the PDO index, but of opposite sign (Deser et al. 2004, their Fig. 4). The NPI is derived from SLP data, whose early record may be more reliable than the early records of SSTs on which the PDO is based (C. Deser 2005, personal communication).

Both the NPI and the CTI are Pacific based and have a very small correlation over the overlapping period of 1899-2002, which is not surprising because they describe variability occurring at different time scales. This makes it worthwhile to study the NPI separately. However, we expect and find similarity in the response of temperature extremes because both the NPI and the CTI invoke circulation changes by similar mechanisms, and because both have similar patterns of sea level pressure and sea surface temperature variability associated with them (see, e.g., discussion in Zhang et al. 1997). The NPI used in this study spans the years 1899 2002, and the determination of positive, neutral, and negative phases was performed in the same manner as for the CTI index (Figs. 1b,e). Deser et al. (2004) identified the periods of 1900-24 and 1947-76 as largely positive phases and the periods of 1925-46 and 1977-97 as largely negative phases (see Figs. 1b,e).

In addition to the two indexes centered on the Pacific, we explored the effects of the NAO. We use an NAO index that is defined as the normalized pressure 
difference between a station on the Azores (Ponte Delgada) and the station Stykkisholmu on Iceland (Hurrell and van Loon 1997; Hurrell et al. 2003) and that is available from January 1865. A range of related NAO indexes are available, based on slightly different stations (e.g., Jones et al. 1997). As described in Hurrell et al. (2003), the NAO is a mode of the large-scale circulation, so it may be better characterized by a spatial SLP pattern than stations. However, pattern-based indexes are available only for shorter time spans. In the recent few decades, the NAO has exhibited an upward trend. We have, therefore, assessed the robustness of our results by using a detrended NAO record spanning the years 1948-2002 and found the results very similar, suggesting that they reflect the true response to NAO variability rather than climate trends.

It has been a point of discussion if the NAO or the NAM (Wallace and Thompson 2002), also known as Arctic Oscillation (AO; Thompson and Wallace 1998), is more useful in describing atmospheric variability in the northern extratropics. We have tested the sensitivity of our results by using an AO index, spanning from January 1899 to June 2003. The AO index was obtained from David Thompson's Web site at Colorado State University (http://ao.atmos.colostate.edu/), which is based on projecting the leading EOF of SLP from $20^{\circ}$ to $90^{\circ} \mathrm{N}$ onto the anomaly field of SLP. The results of our AO index analyses are remarkably similar to our NAO index results. We show results based on the NAO index in the paper because the index record has a longer time span, which is particularly useful for analysis of long station data (see section 6). However, given the very hemispheric scale nature of the temperature responses we see, it is possible that our results are better explained by a hemispheric scale variation in the strength of the westerly circulation such as the NAM.

We do not investigate the response of Southern Hemispheric temperature extremes to changes in the southern annular mode (SAM; e.g., Thompson and Wallace 2000) because reliable data for the SAM are available only for few decades and because data for temperature extremes are sparse in the Southern Hemisphere $(\mathrm{SH})$.

\section{b. Climate extremes indexes}

Indexes that determine the daily variability of temperature and precipitation have been collected by the ETCCDMI. Temporally, some stations have indexes going back to the late nineteenth century, however, coverage is much better during the second half of the twentieth century. Data coverage varies between very densely sampled regions, for example, the United States, South Africa, and Eurasia, and regions with much sparser density, such as large parts of northern Africa or South America. In this study, we focus on indexes for temperature extremes. We analyzed four absolute indexes: TXx, TXn, TNn, and TNx (see description below; Alexander et al. 2006, references therein), and four percentile indexes: TN90, TX90, TN10, and TX10.

The extreme indexes of TXx, TXn, TNn, and TNx constitute the annual or seasonal hottest and coldest instance of daily maximum and minimum temperature, respectively, and are absolute extremes in contrast to the percentile-based indexes described below.

The percentile indexes, TN90, TX90, TN10, and TX10, are calculated based on the 90th and 10th percentiles of daily temperature variability for 1961-90. They consist of a percentage count of the number of days above or below the respective percentile and their calculation uses a method described in Zhang et al. (2005). They are monthly values and relate to the number of available days in a month that meet a quality standard. The TN90 index is a count of daily minimum temperatures exceeding the 90th percentile and can be thought of as a measure of unusually warm nights, whereas TX90 is a measure of warm days (Alexander et al. 2006). Likewise, the TN10 index counts unusually cold nights and TX10, cold days. While the absolute indexes of TXx and the others reveal intensity, the percentile indexes give a sense of the number of days that are affected by the circulation regimes (Frich et al. 2002; Alexander et al. 2006). Note that because the exceedences use thresholds for the 90th and 10th percentile that vary with the seasonal cycle, they count unusually warm or cold days relative to the seasonal cycle; whereas the TXx, TXn, TNx, and TNn are absolute indexes and are, therefore, most likely to occur at the peak summer or winter season. Also, the absolute indexes sample further out in the tail of the daily temperature distribution than the 10th and 90th percentiles.

\section{Methodology}

The NPI and NAO focus on boreal winter circulation and are both considered most relevant for the months of DJFM (Hurrell et al. 2003; Deser et al. 2004). Therefore, for assessing their impact on extremes, those four winter months of climate extremes indexes are averaged to arrive at a winter (boreal) seasonal mean value. In the case of the ENSO analysis, November-April (NDJFMA) for boreal cold season and May-October (MJJASO) for boreal warm season are averaged. Since 6-month averaged indices are used, the effect of lags on the response to El Niño has not been investigated explicitly. Note that, different from Thompson and Wal- 
lace (2001), we use seasonal mean circulation indexes to determine the influence of preferentially positive and negative NAO winters rather than a daily index because indexes of extremes are not available daily.

The monthly climate extremes indexes are then equally averaged to arrive at cold and warm season means. In the case of the NAO and the NPI, all four months of DJFM must be available for producing a seasonal mean. This relatively stringent criterion is particularly useful when considering absolute extremes. In the case of the CTI, we split the data into the dynamically active boreal cold season NDJFMA, and the boreal warm season MJJASO. Four out of the six months are required to produce a half season (note that a test using just the four core winter months for the teleconnections to El Niño produced nearly indistinguishable results, indicating that the differences we show, for example, between the CTI and the NPI teleconnections are real).

Lastly, we use only stations that have at least $30 \mathrm{yr}$ of valid data (not necessarily consecutive), and the analysis is performed over the maximal length of overlap between index data and circulation indexes (at most, 1896 to 2002 for El Niño, 1899-2002 for the NPI analysis, and 1865-2002 for the NAO analysis).

As explained in section 2, the circulation index has been converted to an on/off switch for each season of the study period. This allows for the selection of temperature extreme index seasons that coincide with a particular state of circulation, for example, an El Niñolike Pacific state or a positive NAO. Those selected seasons are then analyzed to determine stations in which the seasonal number or intensity of extremes consistently differs between positive and negative states.

We use the Rank-Sum test, also known as the MannWhitney test. It is a nonparametric test that determines if it is possible to reject the null hypothesis that both samples come from the same population (Johnson 1994; von Storch and Zwiers 1999). In the case of this study, the null hypothesis is the assumption that the distribution of the temperature extreme index during positive circulation phases is no different from that of negative circulation phases. The test first combines a station's values from positive and negative circulation phases. It then sorts the resulting vector into ascending order, that is, the "rank" of Rank-Sum. The ranks are summed as follows:

$$
w_{\mathrm{pos}}=\sum_{i=1}^{n x} R_{i},
$$

where $w_{\text {pos }}$ is the resulting sum of ranks of the positive phase values. The next step is to calculate a statistic for use with tables:

$$
U_{\text {pos }}=n_{\text {pos }} n_{\text {neg }}+\left[n_{\text {pos }}\left(n_{\text {pos }}+1.0\right) / 2.0\right]-w_{\text {pos }},
$$

where $n_{\text {pos }}$ and $n_{\text {neg }}$ are the number of the positive and negative phases, respectively, and $w_{\text {pos }}$ is the positive rank sum found above. When the number of samples in the distribution is large enough, (both $n_{\mathrm{pos}} \geq 8$ and $n_{\text {neg }} \geq 8$, which is the case here because we further limit to $\geq 11$ phases each; Johnson 1994), the distribution of $U_{\text {pos }}$ is nearly normal and a statistic, $Z$, can be found that does not rely on lookup tables (e.g., Johnson 1994) but can instead use a probability distribution function. The statistic, $Z$, is easily calculated using the mean and variance of the number of samples in conjunction with $U_{\text {pos: }}$ :

$$
\begin{aligned}
Z & =\frac{U_{\mathrm{pos}}-\mu_{u_{1}}}{\sigma_{u_{1}}}, \text { where } \\
\mu_{u_{1}} & =\frac{n_{\mathrm{pos}} n_{\mathrm{neg}}}{2} \text { and } \\
\sigma_{u_{1}} & =\sqrt{\frac{n_{\mathrm{pos}} n_{\mathrm{neg}}\left(n_{\mathrm{pos}}+n_{\mathrm{neg}}+1\right)}{12}} .
\end{aligned}
$$

If the probability of obtaining $Z$ is less than, or equal to, the prescribed 0.05 significance level for a normal distribution then the null hypothesis is rejected for this station. We can say that, over the time period, seasons associated with the positive phases of the large-scale circulation differ significantly from seasons associated with the negative phases. The resulting, significant stations are plotted in Figs. 2-6. Because some significant results among a large number of stations are expected from chance alone, we also give the percentage of significant stations found in each test in Tables 1-3.

\section{Results}

All temperature extreme indexes show a substantial response to the three circulation regimes, demonstrating that large circulation regimes affect temperature extremes. The extent to which extremes are affected differently from the mean state is discussed subsequently.

\section{a. El Niño/La Niña}

As stated above, the TN90 index is a count of the percentage of days in which the daily minimum temperature is warmer than the 90th percentile. As can be seen in the top panel of Fig. 2, during El Niño phases there is a worldwide change in the probability of warm nights. Parts of Central and South America, particularly along the west coast; Southern Africa; and Indonesia have up to $12 \%-15 \%$ extreme warm nights rather than the $10 \%$ value for neutral years (indicating an increase 


\section{CTI TN90 NDJFMA Difference El Nino from climate}
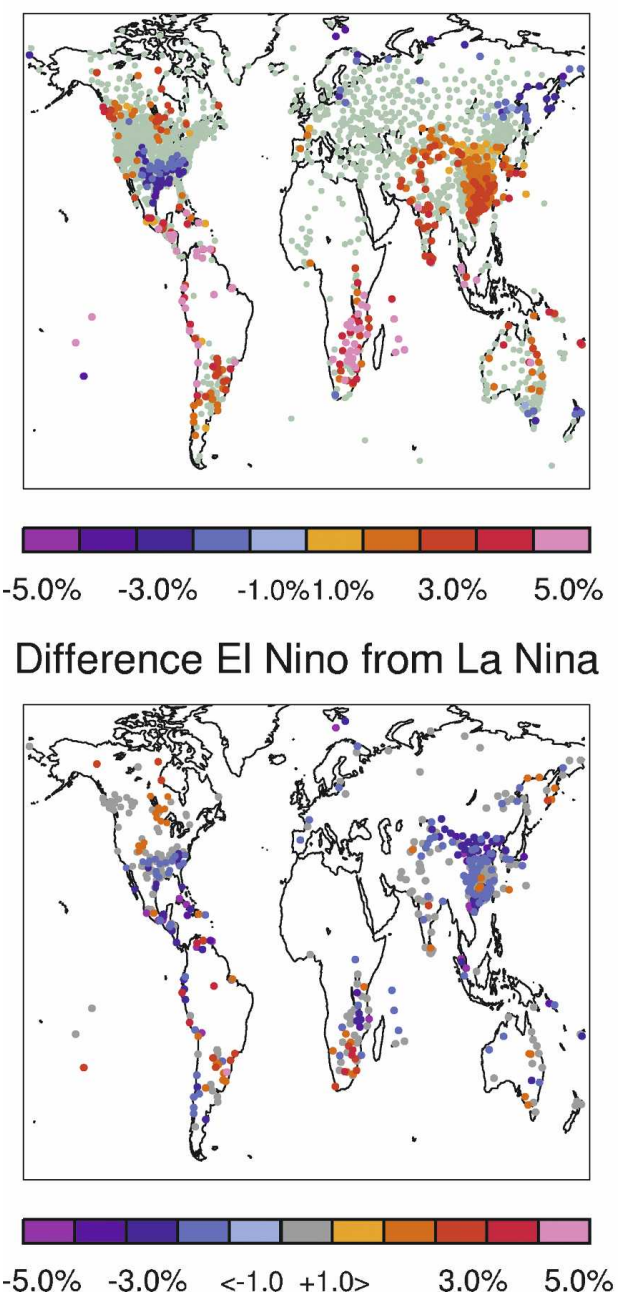

\section{CTI TX90 NDJFMA Difference El Nino from climate}
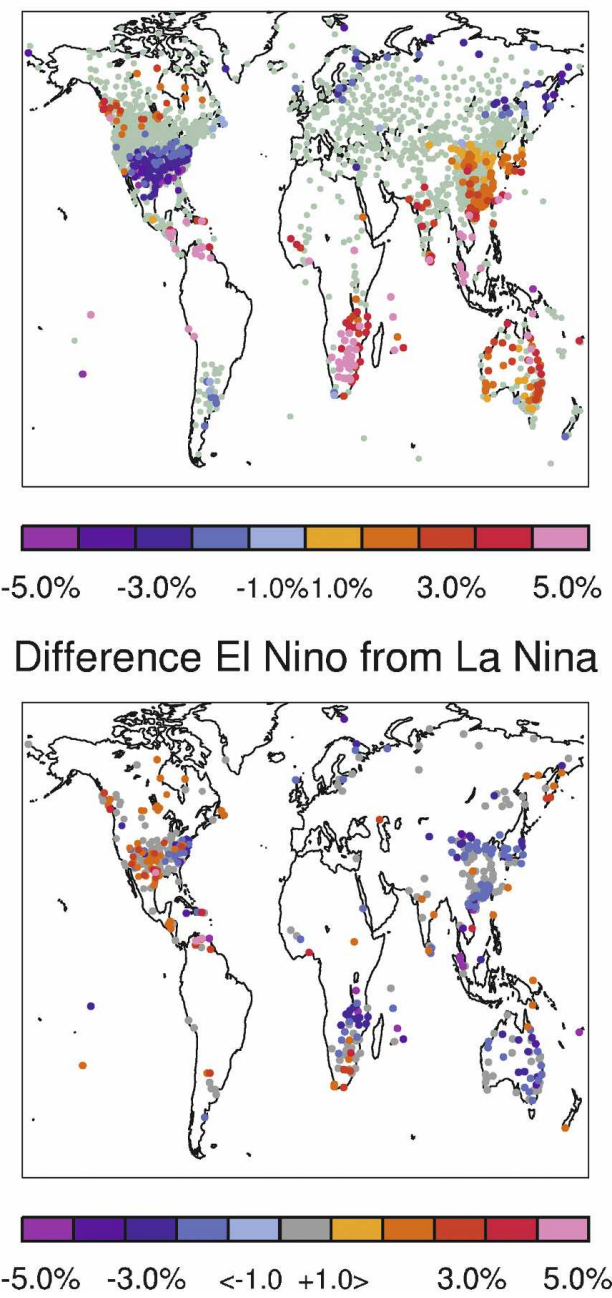

FIG. 2. Difference of mean El Niño years from climatological mean (1961-90) for the number of warm winter (NDJFMA) (left) nights (TN90) or (right) days (TX90). Red colors indicate an increase in the number of warm days (\%). Available stations that do not show a significant response are displayed in light gray. Typical areas of response to ENSO, such as the Pacific Northwest, Peruvian coast, Australia, and India all show a strong warming. Additionally, there is quite strong response in southeast Africa and Central America. Bottom panels show the sum of the El Niño and La Niña responses, and are zero for cancelling values indicating a linear relationship. For example, blue values in eastern Asia indicate a stronger La Niña response.

of up to nine more warm nights in a season over the climatological average), with sub-Saharan Africa showing the overall strongest response. On the Alaskan and Canadian west coasts and for a number of stations across around the center of North America, the number of warm nights increases, whereas the southeastern United States and the Gulf Coast show a decrease of warm nights. This response is consistent with the known response in mean temperature (see, e.g., Ropelewski and Halpert 1986). Eastern Asia and stations in India show a strong warming response, all south of roughly the 40th parallel, whereas poleward, along the eastern Siberian coast, stations experience fewer warm nights. West of this large response, the rest of Eurasia displays a weak or no response. A substantial fraction of stations in Australia (Table 1) also experience more warm nights in response to El Niño during their warm season (NDJFMA). Note also the regional dipole of AustraliaTasmania. Table 1 illustrates that over every continent with data (Eurasia, North America, South America, 


\section{CTI TN10 NDJFMA}

Difference El Nino from climate
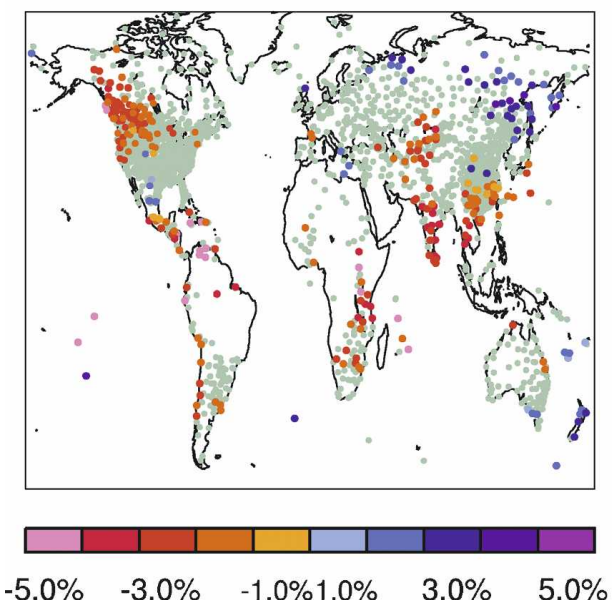

CTI TNn NDJFMA
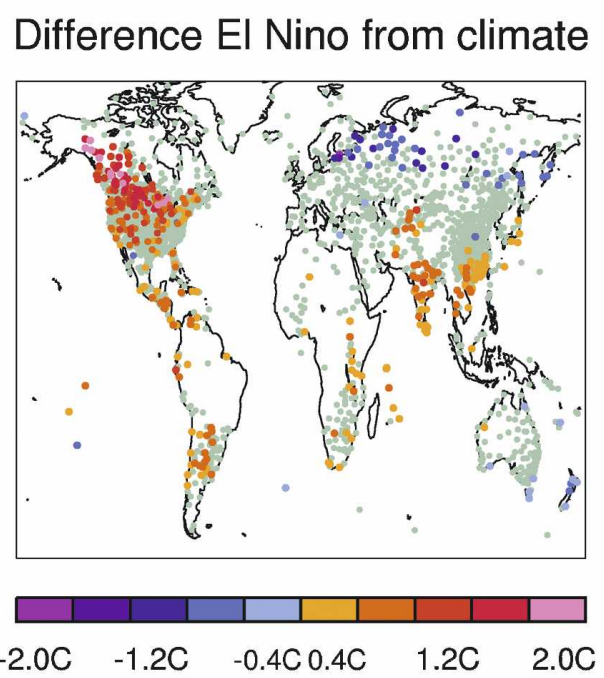

\section{Difference El Nino from La Nina}
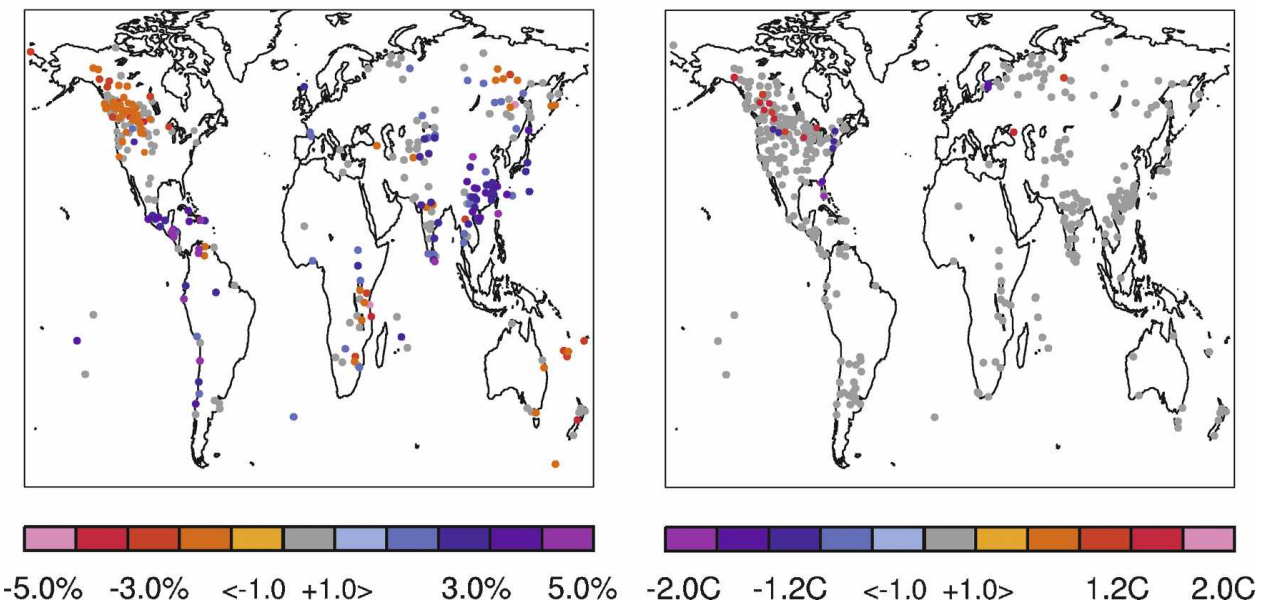

FIG. 3. As in Fig. 2, except for cold winter nights. (left) TN10 shows change in 10th percentile and (right) TNn index shows response of annual coldest night. Color scale is inverted to show a tendency toward fewer extremely cold nights in red colors. The response in both is very strong over North America, India, and parts of Asia, and it shows that extreme nights are less severe during El Niño phases. Results for extremely cold days, TXn, show similar but less robust results.

and Australia combined with southern Africa), substantially more stations than expected show a significant response, with percentages ranging from $27 \%$ (North America) to 51\% (South America). The table also indicates that a change in a similar fraction of stations occurs for the warmest night in the year.

An earlier analysis of extreme temperature indexes versus large-scale circulation was performed with Global Historical Climate Network data (GHCN; Gleason et al. 2002), which was used to construct percentile indexes (TN90, etc.), and the previous generation Global Daily Climate Network (GDCN), which was used to construct absolute indexes ( $\mathrm{TNx}$, etc.). The results based on those data were very similar to the analysis of the ETCCDMI data presented here, but the latter have been quality controlled and are spatially generally more complete. One exception is that, different from the ETCCDMI data, the GHCN-based indexes had more data over Alaska and Japan. The analysis using GHCN data (not shown) shows a significant increase of warm nights over Alaska and down the Alaskan-western Canada coast as well as Japan with El Niño. Otherwise, the step from the GDCN-derived absolute indexes to the ETCCDMI-derived indexes results in a visible im- 

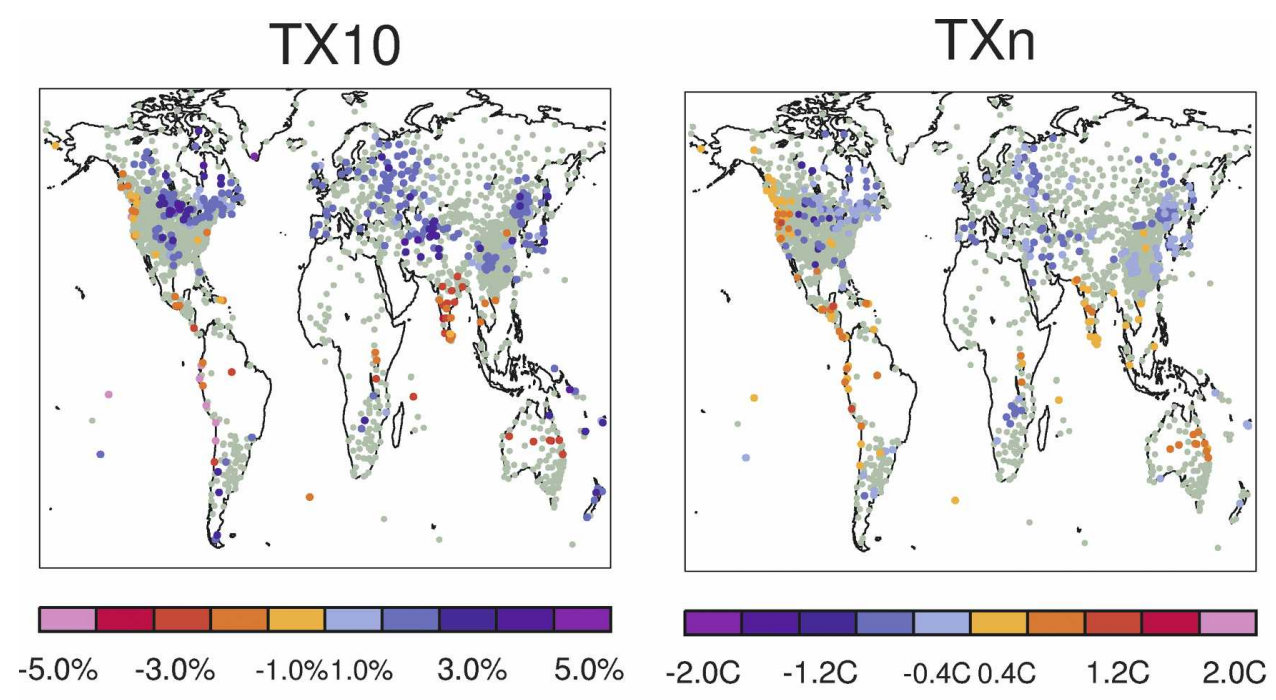

\section{TX90}
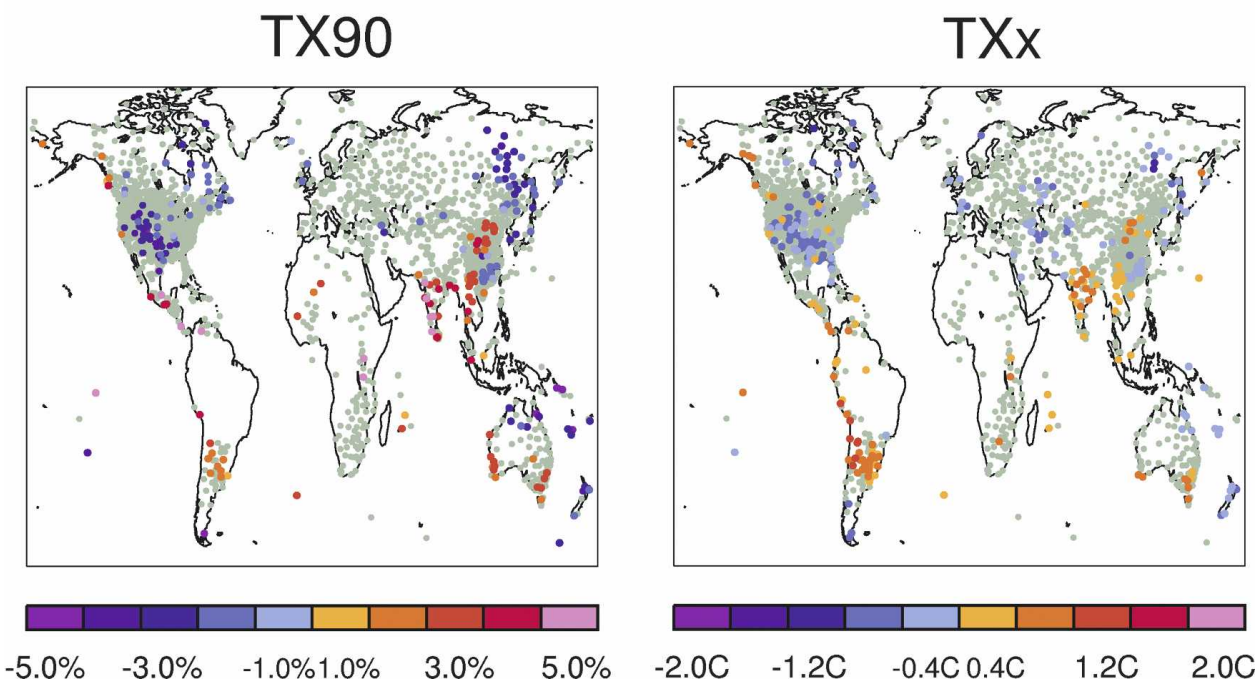

FIG. 4. As in Figs. 2, 3, except showing boreal summer (MJJASO) response of four daytime extremes indexes to El Niño. (top) Cold-day responses; (bottom) warm-day responses. For TX10, color scale is inverted to allow red colors to indicate warm response. Interior North America and Eurasian regions show more cool days during El Niño, whereas Argentina, India, and Australia have more warm days.

provement, with a higher percentage of responding stations and clearer regional impacts. This experience with the three different datasets also applies to our results with the NPI and NAO circulations discussed below.

The response to La Niña is to first order opposite in sign and similar in magnitude to that of El Niño (not shown). To see if the response of TN90 during La Niña phases is exactly the reverse of that seen for El Niño phases, the La Niña response is added to the El Niño response, after scaling both to a response per average positive and negative circulation index for best comparability. This is shown in the bottom panels of Fig. 2 . The differences are often, but not always, close to zero, indicating that response to La Niña is generally of opposite sign and similar amplitude.
El Niño also has a significant influence on warm winter days (TX90), with many significant responses over North America (Table 1; Fig. 2), sub-Saharan Africa, Southeast Asia, and Australia, and few over Eurasia. The pattern differs slightly, with a larger area of decrease in extremely warm winter days in the southern United States extending farther west and showing an overall stronger response. Also, there is less response in the southern half of South America, and the stations that do respond show a decrease in the number of warm days compared to the increase in warm nights with $\mathrm{El}$ Niño. This suggests a change in other climate variables, such as cloudiness. Similar to the TN90 results, there is some indication of a different change between El Niño and La Niña but little systematic changes possibly with 

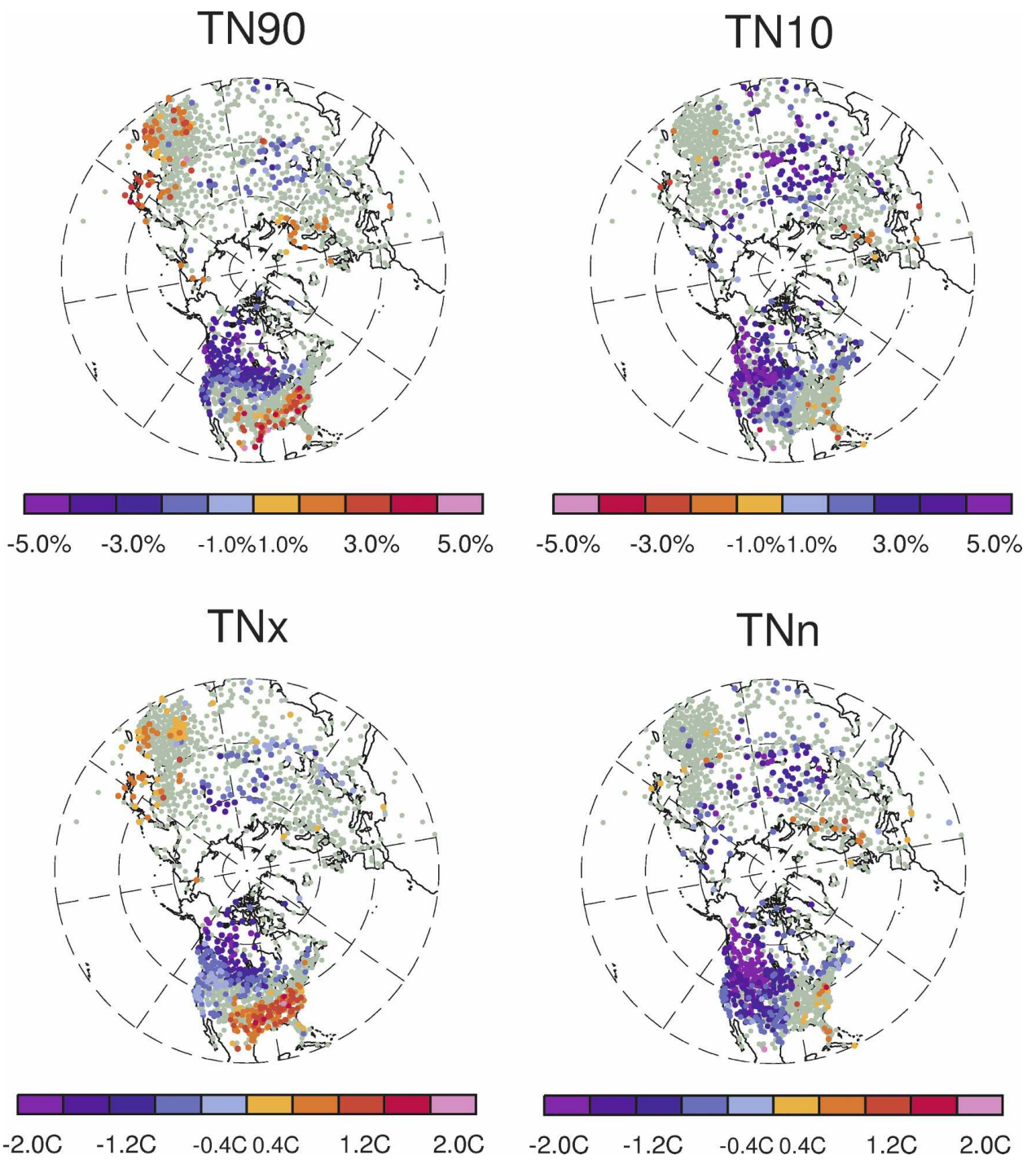

FIG. 5. Stations with significant winter (DJFM) response to the NPI circulation are shown for four of the extremes indexes. (top left) The effect of the positive phase on warm nights. (bottom left) The response of the warmest winter night (TNx). This is useful for determining how the tail of nighttime temperature distribution is affected. (top right) TN10 and (bottom right) TNn indicate how extremely cold nights are affected by the NPI. The regional shape of response is maintained between the percentile indexes and the absolute indexes. Results for cold days are similar. There is also some response in the SH (Table 2), which is similar to that for La Niña (see Fig. 3).

the exception that the decrease in warm nights in the southeastern United States and Southeast Asia seems stronger than the increase with La Niña.

The El Niño index also affects cold extremes. The count of unusually cold nights, TN10, (Fig. 3, top left), shows a strong regional decrease in most of Canada and the Pacific Northwest (and with the GHCN data, Alaska, not shown), but it is not accompanied by any increase in cold nights in the eastern two-thirds of the United States, whereas warm winter nights (TN90) were found to decrease (see Fig. 2). The pattern of response of cold extremes corresponds otherwise to what we would expect based on the change in warm extremes, with stations in Asia and sub-Saharan Africa having a significant response to El Niño (Table 1). TN10 also has a notable response in coastal Siberia, and regions of Eurasia, showing patterns of change in cold nights just as in cold days (Fig. 3, left; Fig. 2, right). The results show that during El Niño phases, nights are generally more often warm and less often cool, whereas during La Niña phases (not shown), the opposite holds true. 
TN90

\section{Difference pos NAO from climate}
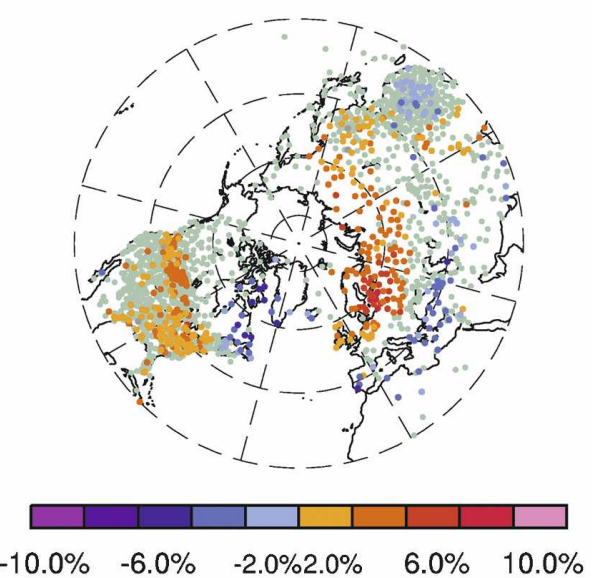

TX10
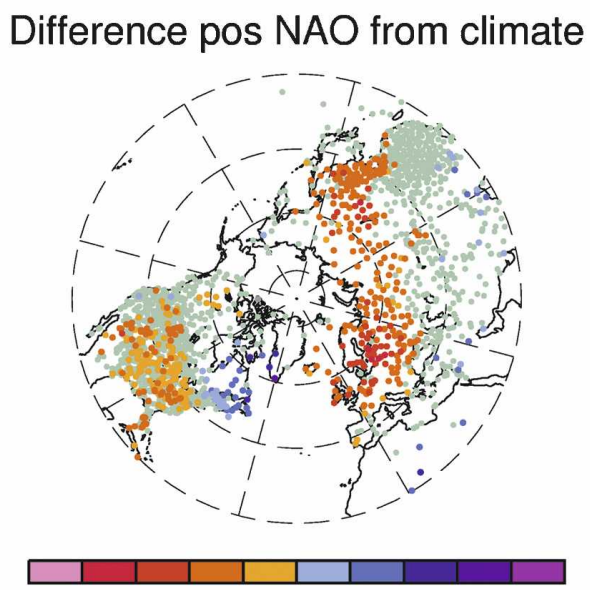

$\begin{array}{lllll}-10.0 \% & -6.0 \% & -2.0 \% 2.0 \% & 6.0 \% & 10.0 \%\end{array}$

Difference pos NAO from neg NAO Difference pos NAO from neg NAO
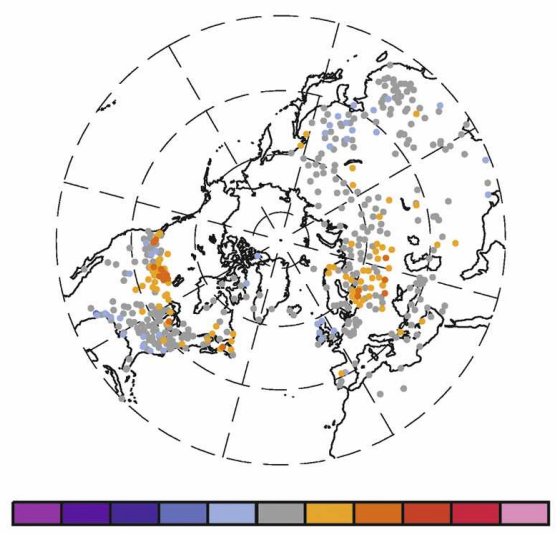
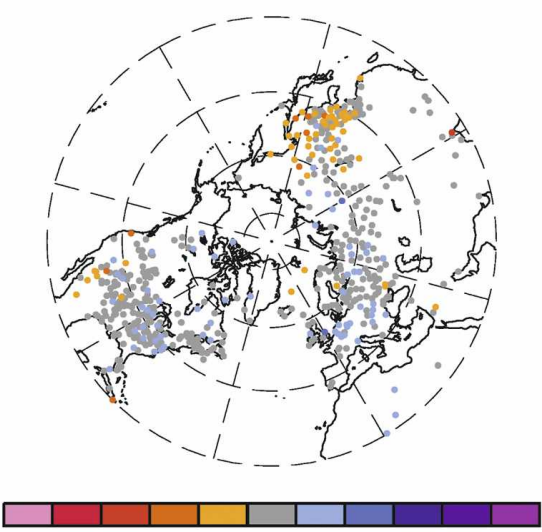

$-10.0 \%-6.0 \%<-0.5+0.5>\quad 6.0 \% \quad 10.0 \%$

FIG. 6. Change in the number of (left) warm winter (DJFM) nights (TN90) or (right) cold winter days (TX10) to positive phase NAO. Bottom panels show the difference in response between positive and negative phases. Warm nights increase during positive phase, and the response pattern is often linear between positive and negative phases. However, there are areas in which the positive phase is noticeably stronger, e.g., Canadian plains provinces in TN90. Results for warm days, TX90, are quite similar to TN90; likewise, the cold night response of TN10 is similar to TX10.

The coldest night of the year is, almost everywhere, significantly warmer during El Niño phases, except for a scattering of far northern Eurasian stations, with more stations significant than for TN10 (Table 1), indicating a particularly strong response for more rare extremes.

Results for summer generally show a weaker influence of El Niño on temperature extremes (Table 1), particularly for warm extremes. There are, however, fewer extremely cool days and nights along the United States and South American west coast (Fig. 4, top), possibly because of warmer waters. India and parts of Australia also experience fewer unusually cool days.
Regions that experience more cool days are the Great Lakes region of North America and stations throughout Eurasia. Similarly, the coldest day (TXn) in boreal summer has a tendency to be warmer along the North American west coast yet slightly cooler in the eastern United States and parts of Eurasia. Note, however, that the absolute coldest warm season (May-October) day may reflect partly the transition season.

The hottest boreal summer days (Fig. 4, bottom) and nights (not shown) show somewhat more erratic influences of circulation, with a general decrease of hot extremes over the United States and Siberia but increased warm extremes in parts of India and Southeast Asia 
TABLE 1. Percent of rank-sum tested stations with a significant response to El Niño (i.e., the CTI) for four regions: North America, South America, Eurasia, and South Africa and Australia combined. The table shows results for indexes based on the exceedence of climatological thresholds. Results for the corresponding most extreme days and nights of the year are given in brackets for comparison.

\begin{tabular}{lcccc}
\hline \multicolumn{5}{c}{ Percent significant stations, ENSO, boreal winter, NDJFMA } \\
\hline & TN90 (TNx) & TN10 (TNn) & TX90 (TXx) & TX10 (TXn) \\
\hline North America & $27 \%(31 \%)$ & $22 \%(22 \%)$ & $37 \%(40 \%)$ & $42 \%(28 \%)$ \\
South America & $51 \%(38 \%)$ & $22 \%(34 \%)$ & $36 \%(31 \%)$ & $28 \%(27 \%)$ \\
Europe-Asia & $33 \%(32 \%)$ & $17 \%(18 \%)$ & $23 \%(25 \%)$ & $14 \%(17 \%)$ \\
South Africa and Australia & $46 \%(45 \%)$ & $23 \%(16 \%)$ & $65 \%(62 \%)$ & $48 \%(37 \%)$ \\
& Percent significant stations, ENSO, boreal summer, MJJASO & \\
\hline & TN90 (TN hi) & TN10 (TN lo) & TX90 (TX hi) & TX10 (TX lo) \\
\hline North America & $14 \%(13 \%)$ & $25 \%(18 \%)$ & $15 \%(11 \%)$ & $25 \%(15 \%)$ \\
South America & $62 \%(70 \%)$ & $13 \%(13 \%)$ & $36 \%(51 \%)$ & $20 \%(21 \%)$ \\
Europe-Asia & $10 \%(10 \%)$ & $24 \%(13 \%)$ & $13 \%(13 \%)$ & $24 \%(20 \%)$ \\
South Africa and Australia & $24 \%(18 \%)$ & $17 \%(18 \%)$ & $24 \%(18 \%)$ & $17 \%(15 \%)$ \\
\hline
\end{tabular}

(see also Table 1). Overall, the boreal warm season results over North America are consistent with the Pacific-North America (PNA) teleconnection of ridging over western and northern North America and a trough over eastern North America as described by Ropelewski and Halpert (1986).

Table 1 further shows that during the warm season, the absolute and percentile extreme indexes have a very similar response to ENSO. This is an improvement over an earlier analysis with the GHCN- and GDCNderived indexes (not shown), and may it indicate the better quality control of ETCCDMI data.

We conclude that the ENSO regime's impact on worldwide temperature extremes is global in scale and particularly pronounced for the boreal cold season. The regime affects the continents bordering the Pacific most profoundly, and it also has a clear impact on land surrounding the Indian Ocean. Note that there are still large gaps in coverage of extremes indexes in South America and Africa.

\section{b. NPI}

During the positive phase of the NPI, the western North Pacific is warm with a weaker Aleutian low, whereas western Canada and Alaska are colder. The NPI impact on the indexes is broadly consistent with the response to El Niño and of opposite sign, which is not surprising given that both are associated with broadly similar patterns of SLP and SST (see, e.g., Zhang et al. 1997; Mantua et al. 1997). Table 2 shows that over North America, the NPI's impact appears more significant on temperature extremes than that of El Niño. The impact of the NPI on temperature extremes is strongest in the Pacific Rim region, with a strong response over eastern Asia and a very strong response over Japan. We focus on the Northern Hemisphere in the figure, where the impacts are clearest. However, the NPI does affect the SH as well, which can be seen in Table 2. South American extremes respond more strongly to the NPI than El Niño for cold daily minima but not daily maximum temperatures. Values for sub-Saharan Africa and Australia combined do not respond as strongly to the NPI as to El Niño. Figure 5 shows the response of the two percentile indexes of TN90 and TN10 to the NPI in the top panels, with the corresponding absolute indexes of TNx and TNn in the bottom panels. As can be seen in Fig. 5 and Table 2, there is great agreement in the regionality of response between the percentile and the absolute indexes. The northwestern two thirds of North America show fewer counts of warm extremes during positive phases of the NPI, whereas the southeastern third of North America

TABLE 2. As in Table 1, except stations are tested for response to the NPI.

\begin{tabular}{lcccc}
\hline \hline \multicolumn{4}{c}{ Percent significant stations, NPI, boreal winter, DJFM } & \\
\hline & TN90 (TNx) & TN10 (TNn) & TX90 (TXx) & TX10 (TXn) \\
\hline North America & $59 \%(53 \%)$ & $55 \%(55 \%)$ & $49 \%(47 \%)$ & $50 \%(48 \%)$ \\
Europe-Asia & $19 \%(18 \%)$ & $19 \%(18 \%)$ & $18 \%(9 \%)$ & $16 \%(15 \%)$ \\
South America & $48 \%(39 \%)$ & $55 \%(57 \%)$ & $20 \%(13 \%)$ & $26 \%(18 \%)$ \\
South Africa and Australia & $23 \%(19 \%)$ & $25 \%(17 \%)$ & $15 \%(12 \%)$ & $19 \%(15 \%)$ \\
\hline
\end{tabular}


TABLE 3. As in Table 1, except stations are tested for response to the NAO. Only Northern Hemisphere regions are discussed.

\begin{tabular}{lllll}
\hline \hline \multicolumn{4}{c}{ Percent significant stations, NAO, boreal winter, DJFM } & \\
\cline { 2 - 4 } & TN90 (TNx) & TN10 (TNn) & TX90 (TXx) & TX10 (TXn) \\
\hline North America & $45 \%(41 \%)$ & $55 \%(39 \%)$ & $45 \%(40 \%)$ & $49 \%(27 \%)$ \\
Europe-Asia & $39 \%(33 \%)$ & $44 \%(48 \%)$ & $55 \%(47 \%)$ & $41 \%(46 \%)$ \\
\hline
\end{tabular}

shows more. The response of Japan and parts of Asia are opposite of those over western North America, experiencing more warm nights and days during positive phase. This is due to the weaker Aleutian low bringing less arctic air down on its western flank (Deser et al. 2004). A stronger low is associated with the negative NPI phase and brings colder air down over Asia, while moving warmer subtropic air from the Pacific to the North American continent and bringing warmer conditions to the western part of the continent. Regional presence of the NPI response is not as strong over the rest of the Northern Hemisphere.

The number of extremely warm days (not shown) shows a decrease similar to that in warm nights in response to the positive NPI over most of North America, again, with a warming response in the central and eastern United States (similar to Fig. 5, top left). This is similar to the results of Deser et al. (2004), who found that wintertime air temperatures over the region $51^{\circ}$ $70^{\circ} \mathrm{N}, 100^{\circ}-175^{\circ} \mathrm{W}$ were cooler during the positive phase of NPI. Their results for the lower, eastern United States were not as pronounced as in this study, but their epochal difference between the 1947-76 period (decadal positive phase) and the 1977-95 period (decadal negative) shows an effect in the southeastern United States that is consistent with our results. The response to the negative phase NPI is largely the reverse of the response to positive phase. For the number of cold and warm days (TX10 and TX90, not shown), stations in North America and central Asia exhibit more cool days during the positive phases of the NPI, whereas eastern Siberia and Japan experience more warm days. The $\mathrm{TXx} / \mathrm{n}$ and $\mathrm{TNx} / \mathrm{n}$ indexes indicate that extreme annual values are warmer during the negative NPI.

The cold extremes indexes of TN10 and TNn get colder or more frequent during the positive phase NPI. Note also that the number of extremely cold nights (Fig. 5, bottom right) changes in northwest North America similarly to that of warm nights.

\section{c. NAO}

When the NAO is in its positive phase, the pressure difference between the Icelandic low and the Azores high is anomalously strong, leading to stronger wester- lies over the North Atlantic region. Because the NAO is mostly a wintertime phenomenon (e.g., Hurrell et al. 2003), we analyze the circulation index and stations only in DJFM. The NAO regime is known to be one of the main influences on European winter weather and our results reflect that. The TN90, TX90, TN10, and TX10 responses to the positive and negative phases are interesting for their similarity to each other across all regions, indicating a tendency for more warm and fewer cold extremes over large parts of the hemisphere. Responses for these indexes range from strong over Eurasia to weaker over North America, which can be seen in Fig. 6 and in correlation plots (Fig. 7, bottom); although the correlation in TX90 is also strong over North America. European and Siberian stations have a strong response to both phases of the NAO and this reflects what many researchers have found (see Hurrell et al. 2003, references therein). However, one North American feature of interest is the significant dipole response between the northeast corner and the rest of the continent. This result is reflective of the findings of Wettstein and Mearns (2002), who investigated NAO impacts on extreme temperatures, and Hurrell and van Loon (1997) and Thompson and Wallace (1998), who also found a "New England dipole" in their results. It has been conjectured by these previous studies that this region is the main location of the jet stream, marking a boundary between cyclonic flow to the north and anticyclonic flow to the south.

Despite the definition of the NAO as variability over the Atlantic sector, it affects temperature extremes all the way to the North American west coast. This is consistent with Thompson and Wallace (2001), who studied the NAM's influence on temperature extremes. It may be because of a strong similarity between the NAM and NAO indexes, which makes it difficult to separate the influence of the purely Atlantic sector variability from that of a hemispheric change in the annular mode, and it indicates that midlatitude westerlies may generally be stronger throughout the Northern Hemisphere during positive NAO winters. Our results were nearly identical if the NAM index was used rather than the NAO index.

During positive phases of the NAO, the DJFM seasonal results for both TN90 and TX10, shown in the top 


\section{CTI TNx NDJFMA}
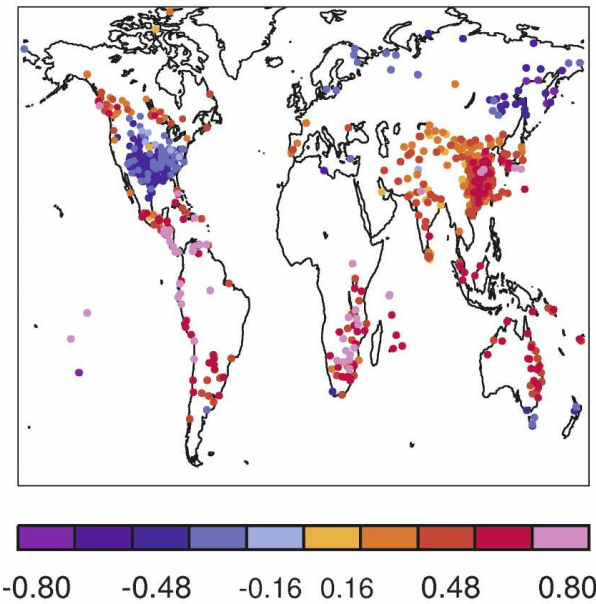

NAO TN90 DJFM

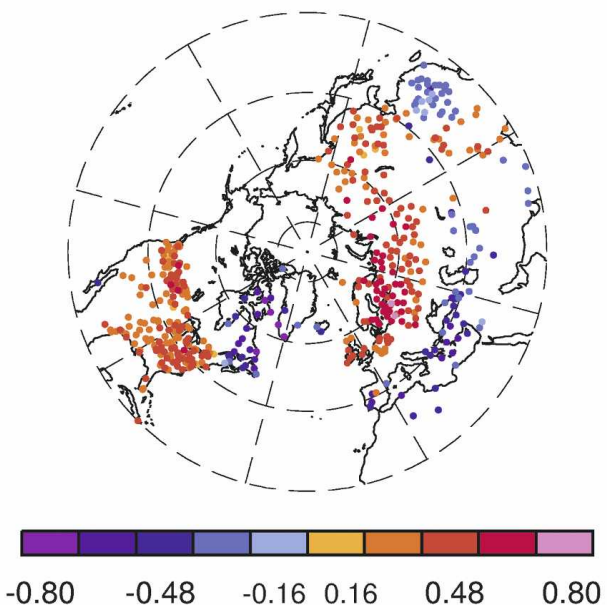

NPI TN90 DJFM
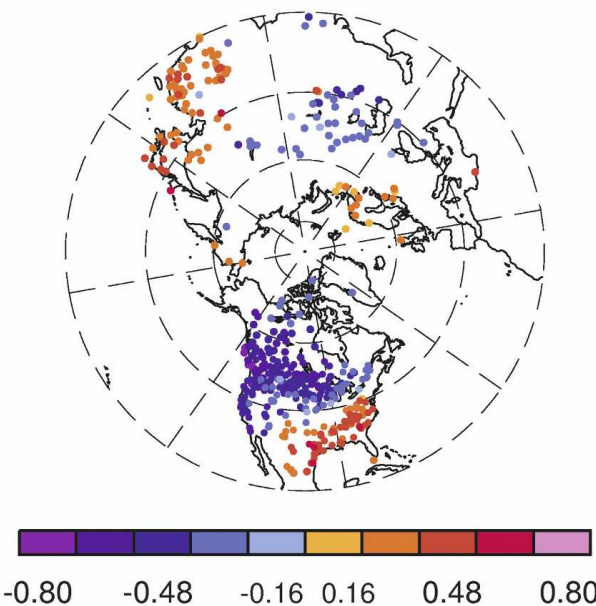

FIG. 7. Correlation plots for four of the circulation/extreme indexes combinations. All plots show correlation of raw circulation index to the extreme index. In some cases, correlations exceed 0.8 between a station's record of a temperature extreme and a particular large-scale circulation.

panels of Fig. 6, show up to $10 \%$ more warm days and up to $10 \%$ fewer cold days across Europe and Siberia, peaking near Scandinavia, which is consistent with Scaife et al. (2008). A very interesting feature is the split along $40^{\circ} \mathrm{N}$ in which the response below this parallel is opposite to that above.

Negative phases of the NAO bring colder temperatures to northern Europe and Asia whereas the Mediterranean region is warmer. Although the difference between positive and negative phases of the NAO is similar and opposite in sign, especially for the TX10 index, there are patches in which the positive phase induces a stronger response (Fig. 6, bottom). In Eur- asian wintertime, TN90 is strongly positively correlated with the NAO, whereas TX10 is strongly negatively correlated.

The responses of the absolute indexes (not shown) are similar to that of the threshold-based indexes (Table 3). Extremely cold days average up to $4+{ }^{\circ} \mathrm{C}$ warmer during positive NAO years, and extremely warm days average up to $2+{ }^{\circ} \mathrm{C}$. The absolute indexes show the same dipole over North America as the percentile indexes.

We conclude that all major indexes of circulation show a substantial and widespread influence on the probability of temperature extremes. Figure 7 shows 
correlation maps for selected results, which illustrate that the connection to circulation explains a substantial fraction with up to a third to half of the variance of changes in seasonal temperature extremes in some regions. The strongest correlations occur between the CTI and stations, and in many cases the correlation is as high as 0.8. The correlation of the NPI and NAO with station indexes is also very strong, with many correlation coefficients for the percentile indexes around 0.6 (Fig. 7); it was also high for absolute indexes (not shown). Thus, a substantial fraction of the variability in extremes indexes originates from these modes of variability (up to $60 \%$ for some regions with CTI and up to $40 \%$ in widespread areas for correspondence to the NAO and the NPI). The correlations of stations to the CTI during the boreal summer season (not shown) are not as strong as those of the boreal winter season, except over Argentina, which would be the winter season for those stations. However, other $\mathrm{SH}$ regions are not as strongly correlated with El Niño during the MJJASO season.

\section{Influence on the shape of temperature distribution}

Results from the previous sections suggest that the response to negative anomalies of circulation indexes is very similar to the negative pattern of response to positive anomalies (see Figs. 2-6). However, the amplitude of the response is often not the same for positive and negative excursions, indicated by regions where the difference value is not that close to zero. To investigate to what extent the response really is linear, and if circulation also affects the shape of the temperature distribution, we have analyzed individual long-record stations separately for seasons in which a circulation index is anomalously high or low. Figure 8 shows how the long, central England daily mean temperature time series (Parker et al. 1992) varies in distribution between winters with positive NAO phase (as defined above) and anomalously low NAO. We used the longer NAO time series from Jones et al. (1997) from 1826 to 2000 [results are similar if the Hurrell and van Loon (1997) and Hurrell et al. (2003) index is used as it is in other parts of the paper] to extend the relationship back as far into the past as possible. Note that it is based on daily mean, not maximum and minimum temperatures. Figure 8 shows that the temperature distribution, for example, reflected by the distance between the 90th and 10th percentile of winter temperatures, as well as by the spread of individual daily values, is substantially narrower for positive NAO years than for negative NAO years or climatology. This is caused particularly by a much wider lower tail of the temperature distribution for negative NAO years. This indicates that in positive NAO years, the more westerly circulation prevents the occurrence of very cold conditions over central England, it but does not have as strong an influence on warm winter days. Similar results were obtained for Greensboro, North Carolina, from the Global Historical Station Network (additional information is available at http://www.ncdc. noaa.gov/oa/climate/ghcn-monthly/index.php), which has data from the late nineteenth century to the present, in which more extremely cold days and nights occurred in winters with a preferably negative NAO (not shown). On the other hand, Greensboro shows a pronounced response to Pacific decadal and ENSO variability. The strongest change occurs in the number of warm winter days and nights (Fig. 8, bottom), which are much more frequent when the NPI is high. This is similar to the effect of La Niña episodes, which results in a diminished trough over the southeastern United States (Ropelewski and Halpert 1986). As proposed by Gershunov and Barnett (1998), a positive NPI would enhance a La Niña episode. In contrast, the lower tail of the distribution in Greensboro is not much affected (see also the difference between TN90 and TN10, Fig. 5). This is again a case where the large-scale circulation not only shifts the temperature distribution, but it changes its shape because of the differences in atmospheric circulation associated with the positive and negative phase. Another station that extends into the nineteenth century, Sacramento (not shown), reaches warmer summer maximum temperatures in La Niña years, whereas winter nights show substantially warmer extremes in El Niño years with little change in the lower tail. The first station is probably driven by the atmospheric response to El Niño, which prevents hot days, whereas the latter station may be a reflection of warmer ocean waters in winter. Sacramento wintertime temperatures are also generally warmer during the negative phase of the NPI.

Thus, consistent with the findings of Thompson and Wallace (2001), the influence of modes of variability is much more complex than a simple shift in mean temperature. This influence does not necessarily affect the probability of warm events at the same rate as that of cold events, and it can affect daytime temperatures differently than nighttime temperatures.

Furthermore, we have compared the strength of the response between positive and negative circulation anomalies. Results show that although the response pattern is similar but opposite in sign for different phases of circulation indexes, not everywhere is the relationship strictly linear (e.g., see Figs. 2, 3, 6; bottom). This is a reflection of the complex nature of telecon- 
a

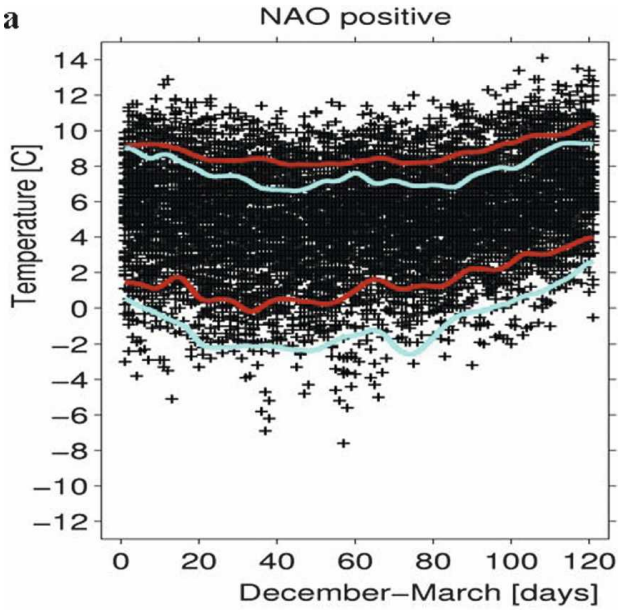

c

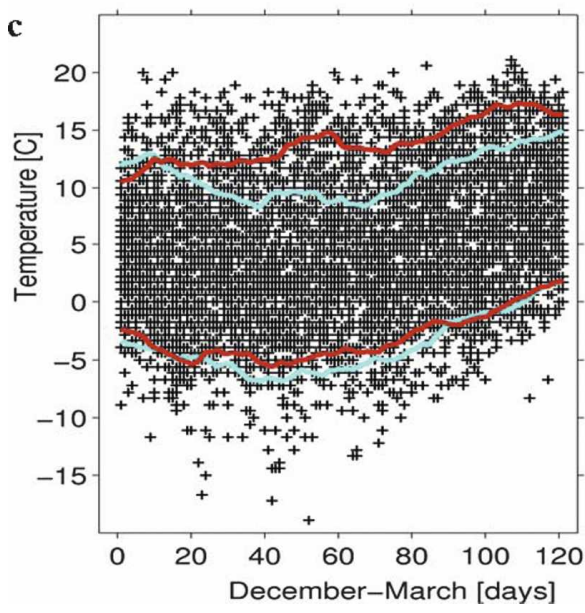

b

14

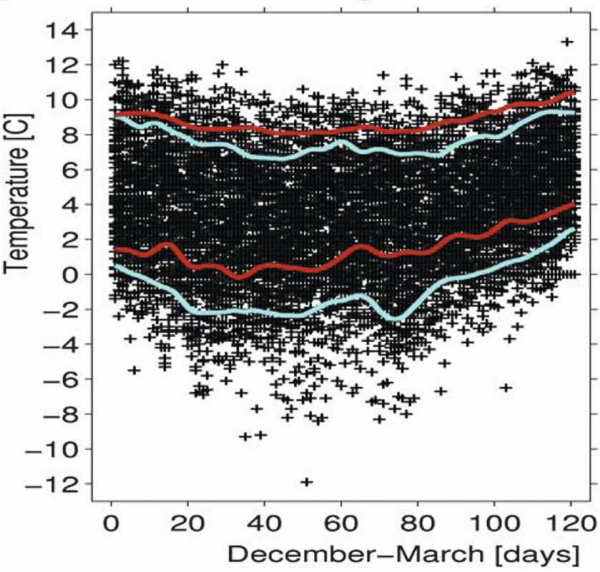

d

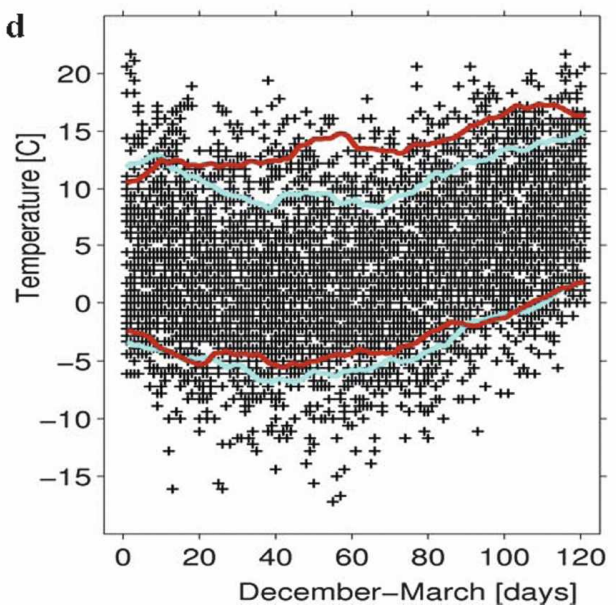

FIG. 8. Seasonal cycle of daily temperature values for central England temperature for (a) positive and (b) negative NAO winters, and for Greensboro for (c) positive and (d) negative NPI winters. Values for individual days from positive circulation anomalies are given in left panels and negative circulation indexes in right panels. For better comparison, the same 10th and 90th percentile lines with positive (red) and negative (blue) circulation anomalies are given in each panel. Thus, the red percentile lines correspond to the crosses shown in the left panel and the blue lines to those shown in the right panel.

nections, which should not be expected to be simple and linear.

\section{Conclusions}

Indexes of temperature extremes for hundreds of stations across the globe were analyzed against the positive and negative phases of large-scale circulation modes. Three indexes describing the state of the largescale circulation were investigated: El Niño-like SST patterns represented by the CTI (note that we use a wider definition of warm conditions than the dynamical El Niño/La Niña condition), the NAO, and Pacific interdecadal variability as represented by the NPI. The extremes indexes that were analyzed were four percentile-based indexes: TN90, TX90, TN10, and TX10, which are percentage occurrences of unusually warm and cold nights and days; and four absolute indexes: TNx, TXx, TNn, and TXn, which indicate the seasonal warmest and coldest night and day.

We found a significant change, both in the number of extremely warm or cold nights (days) as well as the intensity of the most extreme night and day in response to all the modes analyzed. Stations with a significant response were found across the globe, showing that modes of variability of the large-scale circulations have global-scale teleconnection effects. This widespread response of temperature extremes to circulation was observed for all indexes, although Pacific interdecadal variability has its strongest influence near the Pacific Rim and the United States, whereas the NAO influence appears strongest in Eurasia. 
During boreal winter, El Niño causes, sometimes substantially, warmer extremes over most of the globe except in the southeastern United States and coastal Siberia, in which high temperature extremes become fewer or colder. During boreal summer, the response to El Niño is cooler extreme temperatures for the northcentral United States and parts of Eurasia. The North American West Coast and tropical regions are an exception, in which fewer cold days and more hot days are observed, probably because of the direct influence of the ocean.

Positive phases of the NPI cause more warm extremes in the southeastern United States and eastern Asia. Conversely, more cold nights and fewer warm nights affect the rest of North America, especially the northwest to Alaska, and they also seem to affect a region in central Asia.

The NAO/NAM has a significant response over Europe and Asia, and North America. The response in temperature extremes for Eurasia has marked zonal behavior with the response poleward of $40^{\circ} \mathrm{N}$ warmer than the response below, whereas a dipole response exists in the northeast quadrant of North America.

Whereas the typical changes in years with a negative circulation index tend to resemble the reverse of the positive, which suggests linearity, examination of the distribution of daily data at select stations shows that the influence of circulation is more complex. For example, for central England, positive NAO years show a narrower distribution of temperature, with an only slightly changed 90th percentile of winter temperatures but a much narrower lower tail, indicating fewer cold days and nights than years with negative NAO. Similarly, the NPI affects Greensboro, North Carolina, asymmetrically, causing more anomalously warm winter days and nights in its positive phase, although not really affecting cold days and nights.

These results illustrate that modes of climate variability are important drivers of changes in climate extremes. Therefore, changes in modes of climate variability will invariably affect temperature extremes. Some modes of climate variability have already been observed to change, although substantially more in observations than simulations (e.g., Gillett et al. 2005), whereas it is unclear how El Niño and Pacific interdecadal variability will change in the future. This inability to predict changes in circulation quantitatively seriously diminishes our ability to predict changes in regional temperature extremes because these are invariably affected by circulation changes. A further complication is that future El Niño teleconnections may actually change, thus affecting the patterns of extremes over North America (Meehl and Teng 2007; Meehl et al.
2007). Our results demonstrate that for reliably understanding past changes in extremes and reliably predicting future changes, it is essential to account for changes in modes of variability.

Acknowledgments. We thank Xuebin Zhang and Lisa Alexander for providing the temperature extremes indexes and helpful discussion, and Clara Deser for suggesting and providing the NPI and very helpful comments. Additionally, we thank Claudia Tebaldi, Jerry Meehl, Seong-Joong Kim, David Parker, and Francis Zwiers for helpful suggestions and discussion. The authors were supported by NSF Grant ATM-0296007, NOAA Grant NA16GP2683, and Duke University. We are grateful to Byron Gleason for the Global Historical Climatology Network station data.

\section{REFERENCES}

Alexander, L. V., and Coauthors, 2006: Global observed changes in daily climate extremes of temperature and precipitation. $J$. Geophys. Res., 111, D05109, doi:10.1029/2005JD006290.

Arblaster, J. M., G. A. Meehl, and A. Moore, 2002: Interdecadal modulation of Australian rainfall. Climate Dyn., 18, 519-531.

Deser, C., and J. M. Wallace, 1987: El Niño events and their relation to the Southern Oscillation: 1925-1986. J. Geophys. Res., 92, 14 189-14 196.

_ and _ 1990: Large-scale atmospheric circulation features of warm and cold episodes in the tropical pacific. J. Climate, 3, 1254-1281.

— A. S. Phillips, and J. W. Hurrell, 2004: Pacific interdecadal climate variability: Linkages between the tropics and the North Pacific during boreal winter since 1900. J. Climate, 17, 3109-3124.

Folland, C. K., and D. E. Parker, 1995: Correction of instrumental biases in historical seas surface temperature data. Quart. J. Roy. Meteor. Soc., 121, 319-367.

Frich, P., L. Alexander, P. Della-Marta, B. Gleason, M. Haylock, A. M. G. Klein Tank, and T. Peterson, 2002: Observed coherent changes in climatic extremes during the second half of the twentieth century. Climate Res., 19, 193-212.

Gershunov, A., and T. Barnett, 1998: Interdecadal modulation of ENSO teleconnections. Bull. Amer. Meteor. Soc., 79, 27152726.

Gillett, N. P., R. J. Allan, and T. J. Ansell, 2005: Detection of external influence on sea level pressure with a multi-model ensemble. Geophys. Res. Lett., 32, L19714, doi:10.1029/ 2005 GL023640.

Gleason, B., P. Groisman, T. C. Peterson, R. Vose, and R. Ezell, cited 2002: A new global daily temperature and precipitation dataset. [Available online at http://ams.confex.com/ams/ annual2002/techprogram/paper_27803.htm.]

Hurrell, J. W., and H. van Loon, 1997: Decadel variations in climate associated with the North Atlantic Oscillation. Climatic Change, 36, 301-326.

—, Y. Kushnir, G. Ottersen, and M. Visbeck, 2003: An overview of the North Atlantic Oscillation. The North Atlantic Oscillation: Climate Significance an Environmental Impact, Geophys. Monogr., Vol. 134, Amer. Geophys. Union, 1-36. 
Jin, F.-F., 2001: Low-frequency modes of tropical ocean dynamics. J. Climate, 14, 3874-3881.

Johnson, R. A., 1994: Miller and Freund's Probability and Statistics for Engineers. 5th ed. Prentice Hall, 630 pp.

Jones, P. D., T. Jonnson, and D. Wheeler, 1997: Extension to the North Atlantic Oscillation using early instrumental pressure observations from Gibraltar and southwest Iceland. J. Climatol., 17, 1443-1450.

Kiladis, G. N., and H. F. Diaz, 1987: Global climatic anomalies associated with extremes in Southern Oscillation. J. Climate, 2, 1069-1090.

Klein Tank, A. M. G., and Coauthors, 2002: Daily dataset of 20th-century surface air temperature and precipitation series for the European Climate Assessment. Int. J. Climatol., 22, 1441-1453.

Mantua, N. J., and S. R. Hare, 2002: The Pacific Decadal Oscillation. J. Oceanogr., 58, 35-44.

,-- Y Y. Zhang, J. M. Wallace, and R. C. Francis, 1997: A Pacific interdecadal climate oscillation with impacts on salmon production. Bull. Amer. Meteor. Soc., 78, 1069-1079.

Meehl, G. A., and A. Hu, 2006: Megadroughts in the Indian monsoon region and southwest North America and a mechanism for associated multidecadal Pacific sea surface temperature anomalies. J. Climate, 19, 1605-1623.

— connections over North America in a future warmer climate. Climate Dyn., 29, 779-790.

— C. Tebaldi, H. Teng, and T. C. Peterson, 2007: Current and future U.S. weather extremes and El Niño. Geophys. Res. Lett., 34, L20704, doi:10.1029/2007GL031027.

Minobe, S., 1997: A 50-70 year climatic oscillation over the North Pacific and North America. Geophys. Res. Lett., 24, 683-686.

Parker, D. E., T. P. Legg, and C. K. Folland, 1992: A new daily central England temperature series, 1772-1991. Int. J. Climatol., 12, 317-342.

Power, S., T. Casey, C. Folland, A. Colman, and V. Mehta, 1999: Interdecadal modulation of the impact of ENSO on Australia. Climate Dyn., 15, 319-324.

Rasmusson, E. M., and T. H. Carpenter, 1982: Variations in tropical sea surface temperature and surface wind fields associated with the Southern Oscillation/El Niño. Mon. Wea. Rev., 110, 354-384.

Ropelewski, C. F., and M. S. Halpert, 1986: North American precipitation and temperature patterns associated with the El Niño/ Southern Oscillation (ENSO). Mon. Wea. Rev., 114, 2352-2362.

Scaife, A. A., C. K. Folland, L. V. Alexander, A. Moberg, and J. R. Knight, 2008: European climate extremes and the North Atlantic Oscillation. J. Climate, 21, 72-83

STARDEX, 2005: STARDEX: Downscaling climate extremes. Climatic Research Unit, School of Environmental Sciences, University of East Anglia, 24 pp.

Thompson, D. W. J., and J. M. Wallace, 1998: The Arctic Oscillation signature in the wintertime geopotential height and temperature fields. Geophys. Res. Lett., 25, 1297-1300.

— and - 2000: Annular modes in the extratropical circulation. Part I: Month-to-month variability. J. Climate, 13, 10001016.

- , and —, 2001: Regional climate impacts of the northern hemisphere annular mode. Science, 293, 85-89, doi:10.1126/ science. 1058958.

Trenberth, K. E., and J. W. Hurrell, 1994: Decadal atmosphericoceanic variations in the Pacific. Climate Dyn., 9, 303-319.

von Storch, H., and F. W. Zwiers, 1999: Statistical Analysis in Climate Research. Cambridge University Press, 484 pp.

Wallace, J.M. and D. W. J. Thompson, 2002: The Pacific center of action of the northern hemisphere annular mode: Real or artifact? J. Climate, 15, 1987-1991.

Wettstein, J., and L. O. Mearns, 2002: The influence of the North Atlantic-Arctic Oscillation on mean, variance, and extremes of temperature in the northeastern United States and Canada. J. Climate, 15, 3586-3600.

White, W. B., Y. M. Tourre, M. Barlow, and M. Dettinger, 2003 : A delayed action oscillator shared by biennial, interannual, and decadal signals in the Pacific basin. J. Geophys. Res., 108, 3070, doi:10.1029/2002JC001490.

Zhang, X., G. C. Hegerl, F. Zwiers, and J. Kenyon, 2005: Avoiding inhomogeneity in percentile-based indexes of temperature extremes. J. Climate, 18, 1641-1651.

Zhang, Y., J. M. Wallace, and D. S. Battisti, 1997: ENSO-like interdecadal variability: 1900-93. J. Climate, 10, 1004-1020. 